\title{
DAS PIRUETAS AOS SALTOS: AS DIFERENTES MANIFESTAÇÕES DA GYMNASTICA NO RIO DE JANEIRO DA SEGUNDA METADE DO XIX
}

\author{
Anna Luiza Ferreira Romão ${ }^{1}$ \\ Andrea Moreno ${ }^{1}$
}

\begin{abstract}
RESUMO: No Rio de Janeiro oitocentista, a necessidade de se adquirir uma vida saudável pautada em princípios higiênicos e na prática regular dos exercícios físicos ganhava força. A gymnastica, considerada adequada, adentrava instituições diversas. Entretanto, os elementos que a compunham e o discurso que a sustentava se diferenciavam. Ainda assim, em alguns momentos os diferentes modos de se educar o corpo misturavam-se, compartilhando traços característicos e culminando no engendramento do campo da Educação Física. As trajetórias dos professores Paulo Vidal e Vicente Casali são reveladoras desse movimento.
\end{abstract}

Palavras-chave: Gymnastica. Instituições escolares. Instituições não escolares.

\section{From pirouettes to jumps: the different manifestations of gymnastics in Rio de Janeiro of the second half of the XIX}

ABSTRACT: In Rio de Janeiro in the nineteenth century, the need to acquire a healthy lifestyle based on hygienic principles and regular physical exercise gained strength. Gymnastics, considered an appropriate exercise, was adopted by various

${ }^{1}$ Universidade Federal de Minas Gerais, Faculdade de Educaçáo - Belo Horizonte (MG), Brasil. E-mails: annaluizafr@gmail.com, andreafaeufmg@gmail.com DOI: $10.1590 / C C 0101-32622018178336$ 
institutions. However, the elements that composed it and the discourse that supported it differed. Even though, sometimes the different ways of educating the body mingled, sharing characteristic traits and culminating in the engendering of the field of Physical Education. The trajectories of the professors Paulo Vidal and Vicente Casali are revealing of this movement.

Keywords: Gymnastica. School institutions. Non-school institutions.

\section{INTRODUÇÃO}

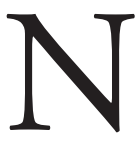

este texto consideramos diferentes espaços de sociabilidade do Rio de Janeiro, os quais, no decorrer da segunda metade do século XIX, acolheram a gymnastica, reconhecendo-a como uma prática capaz de educar os corpos em busca de uma possível saúde dos mesmos e da pedagogização de seus gestos e sentidos. Por terem sido sujeitos centrais nesse processo, enfatizamos a participação de dois daqueles que foram responsáveis pelo seu ensino e que, ao circularem por diversas instituiçóes escolares e não escolares — sistematizando e divulgando seus saberes - , contribuíram com a constituição e com a afirmação da gymnastica. Aqui buscamos, então, compreender de que maneira essa prática se forjava e se afirmava no Rio de Janeiro a partir da intervenção e trajetória dos professores Paulo Vidal e Vicente Casali.

Como professores no Collegio Pedro II (1837) e na Escola Normal da Côrte (1880), na Sociedade Franceza de Gymnastica (1863), no Club Gymnastico Portuguez (1868) e no Congresso Gymnastico Portuguez $(1874)^{1}$, quais foram as práticas defendidas e legitimadas por esses sujeitos no interior dessas instituiçóes? De que maneira se deu o trato com o corpo nesses espaços de sociabilidade? Nos discursos que se articulavam em outras esferas sociais, quais práticas eram negadas e quais eram aceitas? A atuação de Paulo Vidal e Vicente Casali corroborava as noçôes presentes nesses discursos? Tratando-se de lugares distintos, também as práticas se diferenciavam? Quais dispositivos estiveram presentes no engendramento da Educação Física no currículo da instrução pública primária, secundária e de formação de professores e professoras? 


\section{MOVIMENTOS LEGITIMADORES E A PRESENÇA DA GYMNASTICA NO INTERIOR DAS INSTITUIÇÕES ESCOLARES E NÃO ESCOLARES}

Em terras fluminenses, no decorrer dos anos 1800, o processo de aceitação e afirmação da gymnastica foi, paulatinamente, constituindose e ganhando força. Diversos grupos, especialmente aqueles formados por professores, médicos, intelectuais e políticos, iniciaram um debate acerca da necessidade de se adquirir uma vida saudável pautada, sobretudo, nos princípios higiênicos e na realização regular dos exercícios físicos. A gymnastica tornava-se, então, alvo de atenção, principalmente porque seria por meio de sua prática que o corpo se exercitaria e se educaria. Contribuindo, anos mais tarde, para o engendramento da Educação Física no currículo da instrução pública primária, secundária e de formação de professores e professoras, tendo como marco inicial a inauguração da Escola Normal da Côrte, em 8 de abril de 1880.

Articulados e, de certo modo, pressionando o governo para que o mesmo se sensibilizasse acerca dessas questóes, inúmeras reformas no ensino público foram sendo implementadas. Todavia, somente no final da década de 1870 a gymnastica passou a ser considerada uma disciplina obrigatória, tanto nas escolas primárias quanto nas secundárias do município da Corte (Decreto no 7.247, de 19 de abril de 1879). Na Escola Normal, um importante lugar de formação do professorado público de primeiro e segundo graus, a gymnastica foi ofertada desde o primeiro ano de sua existência (Decreto $\mathrm{n}^{\circ}$ 8.025, de 16 de março de 1881) (BIBLIOTECA NACIONAL DO RIO DE JANEIRO, 1881). A princípio as aulas foram destinadas apenas ao sexo masculino, já que, segundo seu diretor, Benjamim Constant Botelho de Magalhães, não havia sido possivel encontrar pessoa édonea para exercer o cargo de professora de gymnastica das alumnas desta Escola (ARQUIVO NACIONAL DO RIO DE JANEIRO, 1881). Foi, somente no ano seguinte, em março de 1882 , com a chegada da professora D. Maria Carolina de Almeida Gouvea (ARQUIVO NACIONAL DO RIO DE JANEIRO, 1882), que as alunas também passaram a praticar a gymnastica².

João Pedro de Aquino, outro diretor e fundador do Collegio Aqui$n o^{3}$, sensibilizado pelas questôes que envolviam a prática ginástica, na década de 1870 , chamava a atenção dos poderes públicos em relação à necessidade 
imprescindivel de dar desenvolvimento ao estudo da gymnastica em todos os estabelecimentos de ensino. Em seu colégio, Aquino entendeu que devia dirigir com mais cuidado a sua attenção para a educação physica, fazendo com que os seus alumnos tivessem sempre exercicios de gymnastica, de esgrima, de dansa e de musica vocal. Assim, aqueles meninos que chegavam ao seu colégio fracos, anemicos, indolentes e melacolicos, tornavam-se, em pouco tempo, fortes, corados, activos e alegres (BIBLIOTECA NACIONAL DO RIO DE JANEIRO, 1878).

Já na década seguinte, um terceiro diretor, agora do Collegio Menezes Vieira ${ }^{4}$, destaca em seu relatório Encerramento dos trabalhos lectivos em 1878 (BIBLIOTECA NACIONAL DO RIO DE JANEIRO, 1878), que em relação à educação physica:

Felizmente parece que a attençáo publica começa a ser attrahida por este assumpto, cuja importancia é incontestavel. A gymnastica escolar, pelo menos, vae adquirindo alguns sectarios entre os rotineiros e os timidos eivados de preconceitos. Não é tudo, mas é alguma cousa (BIBLIOTECA NACIONAL DO RIO DE JANEIRO, 1878).

Mesmo sendo alvo de críticas de alguns segmentos da sociedade fluminense, naquele período, percebemos que a prática dos exercícios físicos, sobretudo nas instituiçóes escolares, começava a calcar seu lugar. Contando, inclusive, com a organizaçáo de alguns grupos que saíam em sua defesa, lançando mão de argumentos voltados à prevenção de doenças e tendo como referência os mais notaveis pedagogistas. Este, talvez, foi o principal argumento que legitimou a sua entrada no âmbito escolar: a gymnastica e a sua capacidade de tornar os corpos saudáveis, já que ficariam isentos da anemia, da escrophulose, da tuberculisação, entre outras doenças que acometiam os fluminenses no decorrer do século XIX (BIBLIOTECA NACIONAL DO RIO DE JANEIRO, 1878).

Outro forte argumento que visava a legitimar a presença e a permanência da gymnastica no contexto escolar, naquela época, foi a ideia de que ela "serviria" como um momento de "descanso" entre as matérias tidas como tradicionais. A gymnastica entra para a escola com o objetivo de "descansar" os alunos, por meio do divertimento5. Todavia, essa forma de "recreação" não seria isenta do controle, da fiscalização. Todos os movimentos deveriam ser escolhidos e indicados de maneira a exercitar, sob o pretexto do jogo, 
todos os músculos da criança, de forma sequenciada, uns depois dos outros. Também aqui, identificamos mais um preceito legitimador da presença da gymnastica nas instituiçóes escolares: o modo de sistematizar os exercícios ginásticos tinha como objetivo desenvolver o corpo de forma harmônica.

Ainda na década de 1880, mais especificamente em 1882, Rui Barbosa, intelectual e defensor da gymnastica, escreve um parecer "Reforma do Ensino Primário e várias Instituições complementares da Instrução Pública” - , no qual sintetiza as medidas que considerava importantes para que a gymnastica compusesse os currículos escolares. Entre as muitas medidas por ele apresentadas, destacamos: a sua obrigatoriedade, a necessidade de se distinguir do recreio e a necessidade de ampliar sua prática, destinando-se a ambos os sexos, guardadas as suas singularidades. Pautando-se em sua capacidade moralizadora e higienica, importante tanto para o físico quanto para o intelectual - imprescindivel à educação do sentimento e do espírito quanto à estabilidade da saúde e ao vigor dos órgáos - a gymnastica, na perspectiva de Rui Barbosa, representava as preocupaçóes da elite brasileira daquele período (BARBOSA, 1946, p. 80).

Em linhas gerais, nesse percurso, os sujeitos, defensores de sua prática, começaram a atribuir à gymnastica a noção de cientificidade, a qual era respaldada pelas ciências biológicas e, por assim ser, recomendada por vários médicos. Nos dizeres de Soares (1994, p. 114-115), a gymnastica tornava-se "um importante canal de veiculação da moral burguesa através de um exacerbado cuidado higiênico com o corpo".

Foi com essas características que a gymnastica se forjou no contexto escolar, inculcando nas crianças e jovens a disciplina, o equilíbrio individual - que pode ser entendido como o controle da vontade, enfatizando o seu viés moralizador — e os hábitos saudáveis — reforçando seu viés higienista. Importa ainda ressaltar que, quando Rui Barbosa diz que o objetivo da gymnastica não é o de transformar os alunos em ginastas, Hercules, ou mesmo em acrobatas, ele está, claramente, se posicionando contra outra forma de manifestação que também se forjava no Rio de Janeiro no decorrer da segunda metade do século XIX ${ }^{6}$. Assim, se pensarmos de forma comparativa, enquanto a gymnastica racional, higiênica, disciplinadora e moralizadora dos hábitos iniciava um processo de aceitaçáo e afirmação no interior das escolas, outra gymnastica já era realizada nos clubes, circos e teatros, compondo o seu cotidiano, naquele período, como veremos adiante. 
Ainda considerando os discursos de aceitação e afirmação no interior das instituiçóes escolares, vale destacar outra importante iniciativa proposta pelo governo: o Congresso da Instrucção do Rio de Janeiro, previsto para 1 de julho de 1883 , no qual se debateria questóes acerca dos problemas educacionais brasileiros. Embora não tenha se realizado, suas atas e pareceres foram publicados em 1884. Em linhas gerais, 29 desses documentos versavam sobre questóes voltadas à instrução primária, secundária e profissional e 17 sobre a instrução superior. A gymnastica, que já se tornara uma matéria obrigatória, também foi debatida. Nesses documentos, vários foram os pontos abordados por diferentes pareceristas. A maioria deles composta por professores públicos primários do município da Corte e autores de livros didáticos publicados entre 1870 e $1880^{7}$.

Alguns pontos merecem destaque: para a maioria dos pareceristas, a educação physica, na educação infantil, deveria primar pelos jogos livres - os exercicios de marcha, as carreiras, os saltos —, os jogos de reflexão e movimento, os quais seriam importantes para fortificar o corpo da criança e, ainda, preferiveis aos exercicios gymnasticos normaes, já que se evitariam os excessos (ARQUIVO NACIONAL DO RIO DE JANEIRO, 1884a; 1884b; $1884 \mathrm{c})$. Portanto, não seriam aceitos exercícios quaisquer, não seria aceito dispêndio de energia e, nesse sentido, os preferíveis eram os exercicios disciplinares e elementares, os passos rithmicos, as marchas, os jogos e uso do portico e seus apparelhos, excepto para o sexo feminino e, claro, dependendo do desenvolvimento e do estado de saude de cada alumno (ARQUIVO NACIONAL DO RIO DE JANEIRO, 1884c). Essa maneira de classificar a gymnastica nos remete a outra concepção legitimadora de sua presença nas escolas, sobretudo, primárias: a gymnastica deveria intervir nos corpos ainda em formação. Nesse sentido, a ela conferiam-se as características de correção, endireitamento, aperfeiçoamento do físico, agilidade, destreza, controle e formação do caráter. Características essas primordiais à infância e à juventude.

Para esse grupo de professores, a gymnastica seria, então, aquela regulada, com movimentos ordenados e metódicos, sem excessos, sem dispêndio de energia; portanto, científica, higiênica, elementar, sistematizada, harmônica, racional, disciplinadora dos hábitos, educativa e obrigatória, contrária àquela gymnastica de saltos forçados e acrobatismo no trapezio. E, atendendo a essas características, ela seria recomendada também às meninas - futuras mãis (ARQUIVO NACIONAL DO RIO DE JANEIRO, 1884b). 
Extrapolando os muros escolares, no Rio de Janeiro dos anos 1800, com os espetáculos musicais e teatrais sendo cada vez mais acolhidos pela sociedade fluminense, crescia a necessidade de uma maior organização e diversificação das práticas corporais. Seguindo rumo à modernização e à urbanizaçâo da cidade, e com o sentimento de progresso pairando sobre a atmosfera da época, muitas associaçóes em que a prática ginástica se fazia presente também foram surgindo. Peres e Melo (2014) ajudam-nos a compreender esse movimento. Em sintonia com as novidades que chegavam do "mundo civilizado europeu", a capital do Império passou a valorizar as "atividades públicas de convivência”. Os Clubs passaram a ser implantados em terras fluminenses.

A Sociedade Franceza de Gymnastica foi uma dessas instituiçóes. Criada em 12 de agosto de 1863, visava a oferecer a uma parcela da população fluminense passatempo agradavel e moral, por meio do estudo da gymnastica, esgrima e musica, sob a direção de professores, e em um local montado convenientemente para recreio, com jogos e saláo de baile (PROVÍNCIA DO RIO DE JANEIRO, 1874, p. 526). Era um espaço de divertimento familiar, embora também esse fosse controlado, uma vez que não era aceito qualquer comportamento, nem se autorizava ali qualquer prática. Somente eram aceitas as práticas lícitas, pautadas na moralidade construída por aquele grupo social, legitimadas e em consonância com aquele contexto que almejava a modernidade, a civilização e o progresso.

A gymnastica, como parte dessa instituição, também comportava essa dimensão controlada do divertimento. Ocorrendo para serem vistas, admiradas, aplaudidas, suas exibiçóes, que também apresentavam elementos característicos do universo circense, visavam à ordem, à limpeza e ao controle dos movimentos. Pautados numa racionalização construída por aquele espaço, executavam-se acrobacias, piruetas, deslocamentos que exigiam força, equilíbrio, destreza, e eram realizados no trapézio, nas barras fixas, argolas e em outros aparelhos ginásticos.

Seguindo essa mesma lógica do passatempo agradavel e do divertimento, surge, em 31 de outubro de 1868, o Club Gymnastico Portuguez. A gymnastica, por sua vez, para se concretizar, também ali assumia a função de divertir a sociedade fluminense. Aqueles que a praticavam executavam exercícios com muita maestria, nitidez e elegancia. As exhibiçóes gymnasticas que compunham as datas comemorativas, os bailes, os saraus e as reunióes familiares despertavam, nos sócios e nos convidados do Club, alegria, entu- 
siasmo, euforia. Os exercicios gymnasticos, dando principio ao divertimento (O PAIZ,1886, p. 2), estavam ali para serem apreciados e aplaudidos por aqueles que os assistiam. O mesmo ocorria com a gymnastica desenvolvida no Congresso Gymnastico Portuguez, criado em 10 de maio de 1874.

Nota-se que, no Rio de Janeiro, forjava-se uma ambiência que propiciava a manifestação dessas diversas formas de divertimento, as quais, além de divertir, também exercitavam o corpo, contribuindo com o processo civilizador e modernizador almejado na época.

\section{COMO SE MANIFESTAVA(M) A(S) GYMNASTICA(S) SISTEMATIZADA(S) POR PAULO VIDAL E VICENTE CASALI: ELEMENTOS CONSTITUTIVOS DESSA PRÁTICA}

Paulo Vidal e Vicente Casali, ao transitarem por diferentes instituições - clubes, escolas, companhias circenses, associaçóes assistenciais, corporaçóes militares, entre outras -, colocaram em circulação discursos, saberes e práticas que, pouco a pouco, contribuíram para a aceitação, a afirmação e a divulgação dessa prática no Rio de Janeiro, no decorrer da segunda metade do século XIX.

Nas escolas públicas, primárias e secundárias, e também naquelas que se destinavam à formação do professorado, a gymnastica sistematizada por esses professores se caracterizava como uma prática racional, higiênica, regulada, elementar, disciplinadora e moralizadora dos hábitos, com movimentos ordenados, metódicos e sistematizados, sem excessos, sem dispêndio de energia. Logo, educativa e obrigatória, tendo, principalmente nesse contexto, a intenção de afirmar um tempo e um lugar específicos à sua prática.

Concretizando-se por meio da prescrição de exercícios específicos para cabeça, tronco, braços, pernas, mãos e pés, a gymnastica buscava desenvolver, de forma harmônica, o corpo em toda a sua extensão. Partia-se do fácil para o difícil; do simples para o combinado, obedecendo a uma determinada ordem e progressão. Levava-se em consideração a aquisição da destreza, da força e da agilidade e, em decorrência dessas, o sistema respiratório, por meio da execução dos saltos, marchas e contramarchas, também se desenvolvia. Por meio dos exercícios de corpo livre, dos exercícios executados com auxílio de apare- 
lhos e instrumentos diversos, a gymnastica estabelecia ritmos comuns e ordens coletivas, controlando a vontade e disciplinando os corpos; por exemplo, por meio das posturas exigidas e da formação de pelotôes. Assim, forjava-se uma educação dos e para os corpos no interior das instituiçóes escolares.

Em outro espaço da cidade do Rio de Janeiro, ainda na segunda metade do século XIX, outra forma de exercícios se manifestava. Privilegiando o entretenimento e o espetáculo, essa gymnastica, desenvolvida nos clubes e associaçóes, dialogava todo o tempo com diferentes esferas da sociedade: o circo, o teatro, o canto, o baile e a encenaçáo. Seus sentidos e significados também eram outros e, desse modo, outra maneira de se educar o corpo se constituía. Na Sociedade Franceza, no Club e no Congresso Gymnastico Portuguez, contando com as contribuiçóes de Paulo Vidal e Vicente Casali, tal gymnastica trazia para a cena a realização de uma prática corporal festiva e desafiadora, mas também controlada, racionalizada e que visava à ordem. Suas exhibiçóes gymnasticas pautavam-se na execução de difficeis exercicios, alguns, inclusive, bastante perigosos. Realizados na barra fixa e horizontal, nas escadas perigosa e milagrosa, no trapezio, no trampolim, nas argolas, no arame e no bambu japonês (DIARIO DO RIO DE JANEIRO, 1871, p. 1; 1873, p. 1; 1885, p. 2; DIARIO DE NOTICIAS, 1886, p. 1; 1887, p. 1; GAZETA DE NOTICIAS, 1885, p. 2), esses exercícios, compostos muitas vezes de acrobacias e voos (DIARIO DO RIO DE JANEIRO, 1871, p. 2; GAZETA DE NOTICIAS, 1884, p. 1), demandavam arriscadas posiçóes de equilibrio, força, agilidade, tendo sido sempre executados com muita perfeição, pericia, destreza e coragem (DIARIO DO RIO DE JANEIRO, 1874, p. 2). Esse conjunto de elementos revela um saber-fazer que se inscreve em comportamentos e rotinas adquiridas, na maior parte das vezes, por meio do trabalho cotidiano das escolas de gymnastica que cada um desses estabelecimentos possuía.

\section{CONSIDERAÇÕES FINAIS}

A gymnastica dos clubes e sociedades foi, nesse percurso, constituindo-se e se afirmando, uma vez que, tendo sido forjada nesses diferentes espaços sob a influência do universo circense, acabou "caindo como uma luva” na nova reorganizaçáo social que estava em curso, rumo à civilização e à modernidade, no Rio de Janeiro. 
Paulo Vidal e Vicente Casali, em suas práticas e ao sistematizarem a gymnastica também no contexto escolar, foram afetados por aquela gymnastica e pelos exercícios que compunham as suas apresentaçóes. Força, destreza, agilidade, coragem, precisão e controle dos movimentos foram alguns dos elementos que os acompanharam, inclusive nas instituiçóes escolares, onde também foram professores de gymnastica, contando com a presença dos aparelhos que, anteriormente utilizados nos clubes, passaram também a auxiliar a execução de determinados movimentos realizados em suas aulas, evidenciando que havia sim uma linha tênue que separava as gymnasticas, mas que não provocava uma ruptura definitiva.

Embora houvesse tensóes e críticas, esses diferentes modos de se educar o corpo misturavam-se, compartilhando alguns de seus traços constitutivos. Portando uma "nova roupagem", as acrobacias e as piruetas executadas nos clubes e sociedades passaram a ser controladas por aparelhos ginásticos e sob a orientação daqueles que eram responsáveis pelo seu ensino nas escolas. As demonstraçóes coletivas das proezas físicas que desafiavam os corpos de seus praticantes e encantavam aqueles que as assistiam, nos diversos espetáculos proporcionados pelos clubes, passaram a fazer parte também das festas escolares. Voltando-se ao espetáculo, sua dimensão do controle não era esquecida. Destinadas à formação do sujeito escolar, à aquisição de hábitos e comportamentos saudáveis, controlados e higiênicos, essas gymnasticas não menosprezavam o divertimento, mesmo porque a lógica do entretenimento se constituiu como um importante elemento na consolidação da sociedade fluminense no decorrer dos anos 1800, tendo sido também mobilizada na construção das representações sobre as gymnasticas.

Portanto, foi nessa linha tênue entre tensóes e negociaçóes de sentidos e significados, nessa amálgama de influências, que se constituíram as gymnasticas, as quais devem ser pensadas em suas pluralidades e na confluência de inúmeros processos culturais, sociais e - por que não? - políticos. E, do mesmo modo, uma determinada forma de se educar o corpo também ia se forjando no Rio de Janeiro da segunda metade do século XIX.

\section{REFERÊNCIAS}

ARQUIVO NACIONAL DO RIO DE JANEIRO. Actas e Pareceres, p. 2, 1884a. 
ARQUIVO NACIONAL DO RIO DE JANEIRO. Actas e Pareceres, p. 5, $1884 \mathrm{~b}$. . Actas e Pareceres, p. 7-8, 1884c.

. Códice: $I E^{5} 28$. Rio de Janeiro, 4 de maio de 1881.

. Códice: $I E^{5} 29$. Rio de Janeiro, 31 de março de 1882.

BARBOSA, R. Obras Completas. Rio de Janeiro: Ministério da Saúde, 1946. v. 10 , t. 2.

BIBLIOTECA NACIONAL DO RIO DE JANEIRO. Prospecto e breve noticia sobre o Collegio Aquino. Rio de Janeiro, s.d. (Obras Gerais).

. Relatorio dos sucessos mais notaveis do anno lectivo de 1881 na Escola Normal da Côrte apresentado á Congregação da mesma Escola em 11 de fevereiro de 1882 pelo Dr. Affonso Carlos Moreira - professor substituto interino. (Obras Completas, v. 6). Rio de Janeiro, 1881.

- Relatorio lido pelo director do Collegio Menezes Vieira por occasião do encerramento dos trabalhos lectivos em 1878. Rio de Janeiro, 1878. (Obras Gerais).

CABRAL, P.L. da C. A aliança dos contrários: a ginástica protagonizada no circo (Brasil, 1840-1880). 189 f. (Mestrado em Educação) - Faculdade de Educação, Universidade Federal de Minas Gerais, Belo Horizonte, 2016.

DIARIO DO RIO DE JANEIRO. Rio de Janeiro, 28 mar. 1871.

. Rio de Janeiro, 13 ago. 1871.

. Rio de Janeiro, 2 nov. 1873.

. Rio de Janeiro, 17 nov. 1874.

DIARIO DE NOTICIAS. Rio de Janeiro, 2 nov. 1885.

. Rio de Janeiro, 16 ago. 1886.

. Rio de Janeiro, 2 nov. 1887.

GAZETA DE NOTICIAS. Rio de Janeiro, 10 dez. 1884.

. Rio de Janeiro, 2 nov. 1885.

O PAIZ. 22 jun. 1886.

PERES, F. de F.; MELO, V.A. de. A introdução da ginástica nos clubes do Rio de Janeiro do século XIX. Movimento, v. 20, n. 2, p. 471-493, abr./jun. 2014. 
PROVÍNCIA DO RIO DE JANEIRO. Almanak Administrativo, Mercantil e Industrial da Côrte e da Capital da Provincia do Rio de Janeiro. Rio de Janeiro, 1874.

ROMÃO, A.L.F. Entre Escolas, Clubs e Sociedades: as Gymnasticas tecidas por professores no Rio de Janeiro (1850-1900). 199 f. (Mestrado em Educaçáo) - Faculdade de Educação, Universidade Federal de Minas Gerais, Belo Horizonte, 2016.

SOARES, C.L. Educação física: raízes européias e Brasil. Campinas: Autores Associados, 1994. 167 p.

\section{NOTAS}

1. Destacamos essas instituiçóes porque, por ambas, fizeram-se presentes tanto Paulo Vidal quanto Vicente Casali - seja como professores de gymnastica, seja (no caso específico de Casali) apresentando-se como artista circense. Para mais informaçōes sobre a circulação desses professores pelo Rio de Janeiro da segunda metade do século XIX e suas atuações, consultar Romão (2016).

2. Para mais detalhes sobre a gymnastica da Escola Normal da Côrte, consultar: Romáo (2016).

3. Paulo Vidal foi professor de gymnastica, nesse colégio, no período compreendido entre 1876 e 1879.

4. Paulo Vidal foi, nessa escola, professor de gymnastica nos anos de 1880.

5. Não por mera coincidência, ao analisarmos alguns quadros de horários de algumas escolas, ao longo do século XIX, percebemos que a gymnastica assume horários de intervalos entre uma disciplina e outra.

6. Para mais informaçóes sobre a gymnastica nos clubes, circos e teatros, bem como a crítica que recaiam sobre aqueles que a praticavam, consultar Cabral (2016).

7. Para mais detalhes sobre o Congresso de Instrucção do Rio de Janeiro e sobre os seus pareceristas, consultar Romão (2016).

Recebido em 24 de abril de 2017.

Aprovado em 12 de setembro de 2017. 